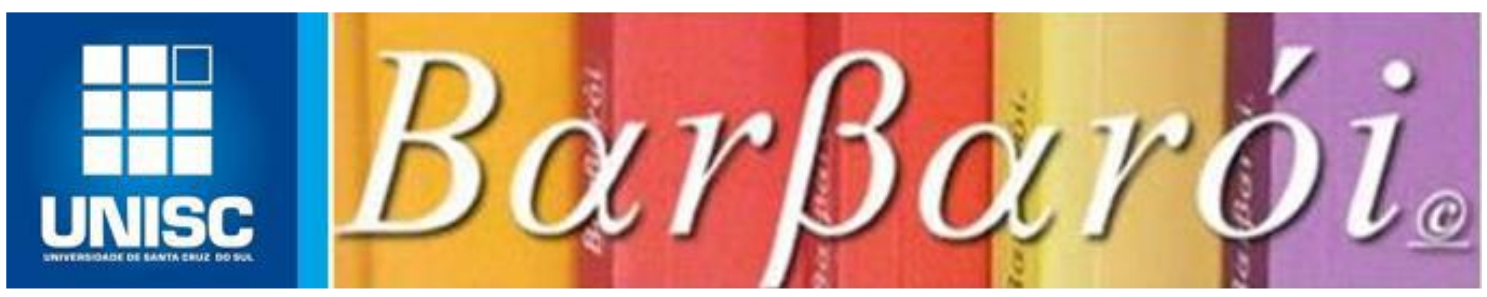

\title{
DIFICULDADES NO ATENDIMENTO ACERCA DA VIOLÊNCIA CONTRA A MULHER, EM GURUPI-TO
}

\author{
DOI: http://dx.doi.org/10.17058/barbaroi.v0i0.12938 \\ $*$
}

\author{
Laslei Aparecida Teles Petrilli \\ Universidade Federal do Tocantins - UFT - Brasil \\ Helga Midori Iwamoto \\ Universidade Federal do Tocantins - UFT - Brasil

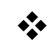

\section{Resumo}

Este trabalho apresenta os resultados das entrevistas semi-estruturadas às equipes da Vara e Delegacia Especializadas no atendimento à mulher vítima de violência em Gurupi, com o objetivo de buscar suas percepções acerca das dificuldades encontradas. Trata-se de uma pesquisa qualitativa, realizada com 15 operadores das duas instituições. As respostas foram analisadas a partir da leitura flutuante e da análise de conteúdo, de Bardin. Seus achados concordam com outras pesquisas na mesma perspectiva, demonstrando que as dificuldades percebidas estão mais relacionadas ao atendimento e acolhimento à vítima do que na realização dos procedimentos legais, necessários e previstos pela LMP. Desta forma os resultados corroboram para a solicitação da implementação da rede de atendimento à mulher, no município, que ainda se apresenta pouco desenvolvida nesta localidade.

Palavras chave: violência contra a mulher; atendimento; equipes.

\section{Introdução}

O comportamento violento, perpetrado por homens contra mulheres, têm sido um elemento natural das experiências de vida de diferentes civilizações, em toda a história. No entanto, no século passado, houve uma evolução na compreensão deste fenômeno, que agora é considerado por muitos: (1) de um ângulo científico, prejudicial para a saúde e o bem-estar das vítimas e suas famílias (MODI; PALMER; ARMSTRONG, 2014); (2) do ponto de vista social, como ilegítimo e antieconômico, levando em consideração as necessidades emergentes em termos de assistência médica, social e jurídica (ALVES, 2016, BECHO et al, 2013, BONOMI et al, 2009); (3) do ponto de vista jurídico, como crime. Entretanto, em muitos países, 
numerosos comportamentos violentos intrafamiliares permanecem tradicionalmente legitimados (ALLEN; DEVITT, 2012, EFE, 2010, FERNÁNDEZ, 2006).

Além disso, o legado cultural e cognitivo da submissão das mulheres às figuras masculinas demonstra a desigualdade de gênero ao longo da história (KORPI; FERRARINI; ENGLUND, 2013, PETER; DROBNIC, 2013) e resulta em crenças enraizadas, negação ou aceitação de tais violências, que são fatos contemporâneos (BOSCH-FIOL; FERRER-PEREZ, 2012, JANKOWSKI et al, 2011, KNICKMEYER; LEVITT; HORNE, 2010, WORDEN; CARLSON, 2005, YAMAWAKI et al.,2012). Esse legado cultural tem um forte impacto na atitude das mulheres, uma vez que sua resposta ao abuso é guiada pelas crenças sobre si mesma, sobre casamento e papéis de gênero (BOONZAIER; DE LA REY, 2004, MEGIAS; MONTANES, 2012).

Achados dos trabalhos de Alves, (2016) revelam que tais crenças muitas vezes se tornam mitos, que frequentemente levam à legitimação ou tolerância da violência masculina e às narrativas que imputem culpa às mulheres (BOSCH-FIOL; FERRER-PÉREZ, 2012, ESQUEDA; HARRISON, 2005, VALOR-SEGURA; EXPOSITO; MOYA, 2011, WORDEN; CARLSON, 2005).

A violência contra as mulheres é um fenômeno que se desenvolve no nível das relações em sociedade, assim, não pode ser entendida, sem considerar a construção social, política e cultural das relações estabelecidas entre homens e mulheres. Portanto, seu enfrentamento requer mudanças culturais, educativas e sociais.

Tal violência compreende atos praticados em ambiente público ou privados e em diversos contextos do cotidiano, porém, é no ambiente doméstico que, fundamentalmente, ela ocorre. É praticada, na maioria das vezes, por homens da família, em relações de poder sobre as vítimas e, ao serem protegidos pelos laços afetivos, podem levar ao extremo as relações de dominação (BARSTED, 2011).

Dentro do contexto da violência contra a mulher, destaque para os governos que devem se esforçar para equilibrar sua legislação com os compromissos firmados e promover as mudanças necessárias nas leis, políticas e programação nacionais. É necessário buscar promover a igualdade de gênero, um direito humano, evidenciando o fortalecimento e compromissos nacionais.

Segundo Piovesan (2006) e Pimentel (1979), a Convenção sobre a Eliminação de todas as Formas de Discriminação contra a Mulher, de 1979, doravante denominada Convenção da Mulher, em vigor desde 1981, foi o primeiro tratado internacional, a dispor amplamente sobre os direitos humanos da mulher. São duas as frentes propostas: promover os direitos da mulher Barbarói, Santa Cruz do Sul, n.54, p.<171-194>, jul./dez. 2019 
na busca da igualdade de gênero e reprimir quaisquer discriminações contra a mulher, nos Estados-parte

Sessenta e quatro países assinaram a Convenção, em 3 de setembro de 1981, que entrou em vigor codificando, de forma abrangente, os padrões legais internacionais para as mulheres. Até outubro de 2005, 180 países haviam aderido à Convenção da Mulher (PIOVESAN, 2006, PIMENTEL, 1979).

Esta Convenção deve ser tomada como parâmetro mínimo das ações estatais na promoção dos direitos humanos das mulheres e na repressão às suas violações, tanto no âmbito público como no privado. Vai além das garantias de igualdade e idêntica proteção, viabilizada por instrumentos legais vigentes, estipula medidas para o alcance da igualdade entre homens e mulheres, independentemente de seu estado civil, em todos os aspectos da vida política, econômica, social e cultural (PIOVESAN, 2006, PIMENTEL, 1979).

Os Estados-parte têm o dever de eliminar a discriminação contra a mulher adotando medidas legais, políticas e programáticas. Entretanto, a declaração formal dos direitos das mulheres não lhes confere automaticamente a efetivação de seu exercício. Depende de ações dos três poderes: do Legislativo, na adequação da legislação nacional aos parâmetros igualitários internacionais; do Executivo, na elaboração de políticas públicas voltadas para os direitos das mulheres; e, por fim, do Judiciário, na proteção dos direitos das mulheres e no uso de convenções internacionais de proteção aos direitos humanos para fundamentar suas decisões (PIOVESAN, 2006, PIMENTEL, 1979).

No Brasil, com a anistia de 1979, a eleição direta de governadores em 1982 e a reorganização partidária, o cenário feminista se fortaleceu, mas se segmentou em grupos partidários. Para atender às demandas de igualdade de gênero foi criado, em 1983, o primeiro Conselho Estadual da Condição Feminina, em São Paulo. Em 1985, criou-se a primeira Delegacia de Defesa da Mulher, órgão eminentemente voltado para reprimir a violência contra a mulher (MASSUNO, 2002).

A partir dos anos 90, com a efetiva participação da Organização Mundial da Saúde (OMS) nas questões de mortes femininas, o tema Violência Contra a Mulher (VCM) adquiriu status internacional, posto que a violência coloca as mulheres numa situação de vulnerabilidade e de perigo, demandando políticas de proteção e apoio (HEISE, 1998; KRUG, 2002).

O ápice dessas conquistas históricas no Brasil, está em 2006 com a promulgação da Lei no 11.340, a Lei Maria da Penha (BRASIL, 2006), que ampliou consideravelmente a visibilidade do problema. Ela institui penas mais severas para os agressores, a criação de 
juizados especiais de atenção à "violência familiar e doméstica contra a mulher", bem como programas e centros de atendimentos aos homens agressores, entre outros avanços.

Especificamente sobre a atuação masculina se tem ainda outra lei importante: a No11.489, de 2007 (Brasil, 2007), que estabelece o dia 6 de dezembro, como Dia Nacional de Mobilização dos Homens pelo Fim da Violência contra as Mulheres, reforçando a Campanha Laço Branco, de mesmo tema, trazida do Canadá desde 1999 (GROSSI, 2008).

Frente ao exposto, a legislação brasileira, por meio da Lei $\mathrm{n}^{\circ} 11.340 / 2006$, ao mesmo tempo em que contempla medidas protetoras voltadas às vítimas e acentua a punição dos agressores, estabelece que o poder público possa promover centros de educação e reabilitação de agressores, com vistas a atuar na constituição de seu comportamento violento. Dessa forma, a aprovação da referida lei favoreceu a construção de um novo lugar para os debates sobre a atenção à violência, no qual os homens autores de violência possam a ser incluídos, segundo estudos de Granja e Medrado (2009).

A Lei Maria da Penha é reconhecida como um marco para o processo histórico de construção e reconhecimento dos direitos das mulheres, como direitos humanos no Brasil. Aclamada pela Organização das Nações Unidas como uma das leis mais avançadas no enfrentamento da violência contra as mulheres no mundo (WOMEN, 2011). Essa legislação contempla medidas judiciais e extrajudiciais adotando uma concepção ampla de acesso à justiça e a direitos, a partir da perspectiva de gênero. Por sua abrangência, o texto legislativo é também considerado um conjunto de políticas públicas para o enfrentamento da violência baseada no gênero, cuja aplicação integral depende do compromisso do Executivo, do Judiciário e do Legislativo, nas esferas do governo federal, dos estados e municípios.

A percepção social da violência contra a mulher é histórica. Pitanguy e Heringer(2002), contam que ao longo dos séculos, essa percepção vem se transformando em função da luta política e social. A mesma mostra o quanto não é natural esse tipo de violência, tornando-a visível e, recentemente, qualificando-a como uma violação dos direitos humanos e como um comportamento criminal. Desse modo deve ser combatida pelos profissionais que lidam com as vítimas. A violência de gênero tem um forte componente cultural, que não é facilmente superado por meio de leis e normas.

De acordo com o relatório "Progresso das Mulheres/2003-2010" (BARSTED; PITANGUY, 2011), a aprovação da Lei Maria da Penha representa a força do movimento feminista brasileiro em sua contínua busca de espaços de diálogo com os poderes da República, em prol dos direitos das mulheres. 
O Supremo Tribunal Federal (STF), em uma manifestação, reconheceu a desigualdade entre homens e mulheres. Assim, determinou que a prática de violência doméstica contra as mulheres leve o agressor a ser processado criminalmente, independente da autorização da vítima. Determinou, ainda, que os crimes contra as mulheres devem ser julgados nos juizados/varas especializadas de violência doméstica e familiar, com competência cível e criminal e que ela seja assistida por uma equipe multidisciplinar (Psicólogo e Assistente Social) treinados para atender (BRASIL, 2002).

No estado do Tocantins funcionam no estado 24 Unidades Especializadas de Atendimento (UEA), representando 3,19 unidades para cada 100 mil mulheres residentes no estado, uma taxa superior à média nacional. Mesmo assim, a violência letal aumentou $40 \%$ na taxa de homicídios de mulheres brancas e 35\% de mulheres pretas e pardas, entre os anos de 2006 e 2014.

Nos estados de Tocantins, Bahia e Maranhão, as taxas de homicídio de mulheres brancas apresentaram, entre os anos de 2006 e 2014, incrementos superiores aos das taxas de homicídio de mulheres pretas e pardas, merecendo um estudo mais aprofundado por serem exceção ao padrão nacional (BRASIL, 2016).

Em Gurupi, de acordo com dados colhidos na plataforma de Gerenciamento de Procedimentos Policiais (GERPOL), desde 2015 os dados de violência doméstica voltaram a crescer, passando de 73 casos relatados em 2015, para 90, até outubro de 2017. Vale ressaltar que em 2014, foram constados 118 registros durante o ano inteiro, número que até outubro de 2017 parece estar voltando a crescer depois de um intervalo de queda.

Segundo dados da polícia civil de Gurupi, do total de ocorrências registradas em todas as delegacias em 2017 (3731 casos) apenas 874 resultaram em procedimentos. No relatório individualizado da Delegacia da Mulher, no mesmo período, obteve-se um total de 361 ocorrências registradas contra a mulher, das quais apenas 144 foram instaurados procedimentos. Este número sugere que Gurupi/TO segue a tendência nacional de violência contra a mulher (TOCANTINS, 2017). Os índices apresentados se resumem aos dados da Polícia Civil de Gurupi e não representam dados judiciais ou ocorrências atendidas pela Polícia Militar, nem mesmo os casos atendidos nos hospitais.

Para dar suporte a pesquisas desta natureza, convém considerar a abrangência das medidas e ações previstas tornando essa Lei, uma política de enfrentamento à violência contra a mulher. A LMP também inclui inovações no tratamento judicial da violência doméstica e familiar, ampliando a participação de outros setores no atendimento às mulheres, na proteção de direitos e na prevenção.

Barbarói, Santa Cruz do Sul, n.54, p.<171-194>,jul./dez. 2019 
Ainda não são todos os casos que chegam até a denúncia, ou a um pedido de socorro, mas como bem coloca Pasinato (2006), o primeiro atendimento dado à mulher é de extrema relevância. Esse momento passa a ter papel crucial sobre as decisões que ela tomará quanto a permanecer na relação violenta ou buscar novas saídas para sua vida.

A Norma Técnica de padronização das delegacias especializadas de atendimento às mulheres (BRASIL, 2010) sugere que a DEAM, por integrar uma rede de serviços, atue como porta de entrada para os serviços de atendimento, devendo indicar e mesmo acompanhar as usuárias até os mesmos. Essa rede, quando completa, deve oferecer os seguintes serviços: orientação jurídica, assistência psicossocial, proteção da integridade física, repressão/criminalização da violência, campanhas educativas sobre violência de gênero, entre outros (BRASIL, MEC, 2010).

Interessante destacar o trabalho executado pela equipe da Dra. Wânia Pasinato e colaboradores que apresentam os resultados da pesquisa "Violência Contra a Mulher e Acesso à Justiça" (2013), elaborado e executado pela CEPIA - Cidadania, Estudos, Pesquisa, Informação e Ação com apoio da Fundação Ford. A CEPIA, ao longo dos últimos 23 anos, tem atuado sistematicamente para que a distância entre leis e realidade seja superada por políticas públicas eficazes, ampliando o acesso à justiça.

Trata-se de um estudo comparativo entre cinco capitais brasileiras e que teve como objetivo refletir sobre a efetividade da aplicação da Lei 11.340/2006 - a Lei Maria da Penha - e seus efeitos para a ampliação do acesso à justiça para as mulheres em situação de violência doméstica e risco social. O referido estudo demonstra ser um investimento para a verificação se essa engrenagem da política pública brasileira está efetivando sua função. Foi realizado estudo comparativo, de natureza qualitativa, calcado em estudos de caso que foram realizados nas cinco capitais: Porto Alegre, Recife, Rio de Janeiro, Salvador e São Paulo. A escolha dessas cidades foi orientada por uma análise preliminar sobre as condições existentes para a aplicação da lei, em cada localidade, especialmente sobre os serviços especializados nos setores de segurança e justiça (PASINATO, 2013).

A pesquisa procurou investigar como essas condições impactam sobre a aplicação da lei e como os operadores do direito avaliam sua efetividade e as dificuldades com as quais se defrontam no cotidiano (em termos processuais e de adequações das medidas às leis vigentes) e como procuram superar essas limitações. Trouxe um diagnóstico acerca da aplicabilidade da LMP nas áreas da segurança e justiça: estrutura, integração e percepções entre os operadores do direito, que contribuiu muito para o entendimento do como se efetiva esse serviço e o que precisa ser melhorado (PASINATO,2013).

Barbarói, Santa Cruz do Sul, n.54, p.<171-194>,jul./dez. 2019 
Machado, (2002) Blay, (2003), Pasinato e Santos, (2008) ao tratar da desigualdade de gênero concordam que, na pauta do movimento brasileiro, a luta pelo reconhecimento da violência doméstica é uma das principais violências que atingem a mulher tornou-se prioridade. Relevante enfatizar que crimes e decisões jurídicas, envolvendo homens e mulheres de destaque na mídia, deram maior visibilidade às ocorrências de violência conjugal contra a mulher. Quando levados a julgamento, os autores da violência eram costumeiramente defendidos com base no sofrimento causado pela rejeição da mulher amada e no princípio de "legítima defesa da honra".

O Observatório da Mulher Contra a Violência (BRASIL, 2016, p. 36), informa que de acordo com dados do Conselho Nacional de Justiça, em 2016, foram instaurados, em todo o Brasil, cerca de 270 inquéritos policiais, concedidas pouco mais de 180 medidas protetivas e iniciados ao redor de 12 processos de execução penal, em casos relativos à violência doméstica contra mulheres (todos os indicadores relativos ao número de registros por grupo de 100 mil mulheres). Portanto, é possível estimar que, a cada 20 inquéritos policiais abertos, são concedidas 13 medidas protetivas e apenas 1 condenação penal do agressor.

Segundo o T1 Notícias (2009), nos dados do Tribunal de Justiça do Tocantins (TJ-TO), a violência contra a mulher contabiliza um total de 3.593 mil casos com condenação, com ou sem a morte da vítima. Nos três últimos anos, a Justiça do Tocantins concedeu 5.864 medidas protetivas para mulheres que alegaram sofrer violência doméstica, por parte dos companheiros ou ex companheiros.

Estes dados mostram a relevância do tema e justificam pesquisas, como esta, que desvela a realidade da violência contra a mulher e os atos desenvolvidos pelos entes públicos (Delegacias e Vara Especializada) responsáveis pela investigação, processo e sanção aos infratores.

Foi realizada pesquisa qualitativa com objetivo de buscar a percepção acerca das dificuldades, que os sujeitos que fazem parte das equipes de atendimentos na Vara Especializada no Combate à Violência Contra a Mulher e Delegacia Especializada no atendimento à mulher, no município de Gurupi-T, enfrentam ao lidar com os atendimentos à mulher, vítima de violência por parceiro íntimo.

A pesquisa foi realizada em visitas periódicas de maio a setembro de 2018 na Vara Especializada de Combate a Violência Doméstica e Familiar contra a Mulher e Delegacia Especializada no Atendimento à Mulher (DEAM), de Gurupi-T, local de onde partem as denúncias. Foram feitos os contatos e agendadas as entrevistas. 
Identificada e devidamente apresentada à equipe de atendimento às mulheres, 15 pessoas no total dos participantes concordaram, assinando o TCLE - Termo de Consentimento Livre e Esclarecido e concedendo as entrevistas, de acordo com as disponibilidades individuais. A equipe da Vara é constituída por um juiz titular, um assessor, um escrivão, dois técnicos judiciais, um assistente social e um psicólogo, totalizando sete (7) indivíduos. A delegacia conta com uma delegada titular, duas escrivãs, uma assistente administrativo e quatro agentes da Polícia Civil, totalizando nove (9) indivíduos.

Os componentes das equipes foram identificados pela letra $\mathbf{E}$, numerados de 1 à 15 , preservando sua identificação. Neste artigo as perguntas estão dispostas em forma de afirmações, compondo subtítulos na apresentação dos dados e discussões.

Os dados foram tratados de forma qualitativa, visando compreender as percepções pessoais das equipes nas duas instituições pesquisadas. Como as transcrições são fidedignas e totais, a análise foi realizada por meio da leitura flutuante, que segundo Bardin (2011), é o primeiro contato com os documentos da coleta de dados, momento em que se começa a conhecer os textos, entrevistas e demais fontes a serem analisadas.

Ainda, com vistas a responder ao objetivo da pesquisa, os dados foram analisados por meio da análise categorial, que, conforme Bardin (2011), consiste no desmembramento do texto em categorias agrupadas analogicamente. A opção pela análise categorial se respalda no fato de ser a melhor alternativa quando se quer estudar valores, opiniões, atitudes e crenças, através de dados qualitativos, que foram previamente programadas no roteiro de entrevista aplicada.

Assim os resultados obtidos após a análise das entrevistas, foram dispostos respondendo aos sete questionamentos, que procuraram desvendar as dificuldades, dos componentes das duas equipes, ao realizar atendimentos às mulheres, vítimas de violência por parceiro íntimo.

\section{Percepção das equipes acerca das dificuldades do atendimento à mulher vítima de violência por parceiro íntimo}

Em um total de 7 (sete) perguntas se buscou levantar as dificuldades dos 15 (quinze) integrantes das equipes de atendimento da Vara Especializada no Combate a Violência contra a mulher e da Delegacia Especializada, ambas em Gurupi, Tocantins, e cada uma delas está disposta, na forma de subtítulo, com a devida apresentação e discussão dos seus achados.

\section{Importância do treinamento profissional}

Todos os entrevistados concordam com a necessidade de ter treinamento, para pleno atendimento às mulheres.

E 4- "sim, eu acredito que é importante o treinamento, e acredito que é bom ter mulheres atendendo mulheres, porque mulher é mais sensível, eu vejo assim as vezes a figura do policial, policial já tem as vezes aquele treinamento mais bruto né, e as Barbarói, Santa Cruz do Sul, n.54, p.<171-194>,jul./dez. 2019 
vezes sem perceber pode ofender a mulher e a mulher fica magoada, então eu entendo que é bom a maioria de vara especializada da mulher, vara de violência contra a mulher, ter mulheres para atender as vítimas, pra que elas se sintam mais à vontade prafalar"

E 9- "quando as mulheres chegam aqui elas já chegam sensibilizadas né, e a gente tem que ter todo uma ...pra recebe-las né, um jeito próprio pra atender da melhor forma possivel...

Pesquisa desenvolvida por Pasinato (2008), revelou que, embora as cinco capitais (Porto Alegre, Recife, Rio de Janeiro, Salvador e São Paulo) representem realidades diferentes as dificuldades são comuns e resultam da falta de investimento público para a criação das estruturas necessárias, a formação de recursos humanos suficientes, adequados e capacitados

para o atendimento da violência baseada no gênero. É necessário conhecer e compreender as especificidades da violência baseada em gênero. No que se refere à falta de especialização dos profissionais, esta é um obstáculo ao acesso das mulheres à justiça podendo ocorrer e repetirse em diferentes momentos do atendimento, desde a solicitação de informações, até decisão judicial.

Concordam com o treinamento e admitem a necessidade do mesmo, já que na área de formação da maioria, estes conhecimentos não foram abordados. Assim buscou verificar a importância no treinamento específico para os membros das equipes.

\section{Necessidade do treinamento profissional para atender casos de violência doméstica}

Todos os 15 entrevistados concordam com a importância do treinamento para auxilialos nos atendimentos às vítimas. São algumas colocações:

E 3- "porque talvez a gente faria uma melhor prestação emocional"

E 5- “sim, ... não temos esse tipo de treinamento, treinamento aqui é feito na base aqui da realidade, da experiência, do dia a dia, mas é de suma importância, não é assim, teria que ser uma coisa a cada 6 meses mesmo, reciclagem, vem aqui porque as vezes o que acontece, de tanto uma situação, a gente vai trabalha, mas a vítima diz "não, estava de cabeça quente não quero mais", e acaba que você fica "poxa mas a gente fez tudo e agora a vítima retrata”, mas tudo bem, a gente não culpa nem nada, faz nosso serviço, mas acaba que de tantas vezes acontecer isso vai perdendo um pouco a sensibilidade, então a cada, eu por mim, ter uma reciclagem "gente não se esquece, não perde a finalidade", discutir casos assume "olha esse caso aqui teve isso, vamos ter mais sensibilidade, não vamos perder".

E 8- ", treinamento claro é bom pra toda equipe, mas o ideal mesmo é ter a equipe multidisciplinar, o psicólogo a nossa disposição o tempo todo, pra tanto atender a vítima quanto os agressores..."

E 14- "ah, eu acho que um treinamento seria ótimo, de como atender, o que falar, como agir..." 
E 15- "ah, eu acho que ter mais embasamento técnico na hora de conversar na hora de acolher, na hora de receber essa mulher, que chega tão fragilizada."

Contudo, se a experiência cotidiana e o conhecimento técnico são fundamentais e devem ser valorizados na busca de soluções, é igualmente indispensável que a especialização da atenção seja construída a partir de bases compartilhadas de conhecimentos, conceitos e metodologias que possam ser mobilizados através de protocolos e intervenções interdisciplinares. Nesse aspecto, parece importante ousar na formação dessas/es profissionais, tornando os conteúdos de cursos mais atraentes através do emprego de novas tecnologias e recursos didáticos, incentivando o pensamento crítico e a autorreflexão a partir das práticas cotidianas que se espera modificar (PASINATO, 2013).

A falta de protocolos para o atendimento e os encaminhamentos são obstáculos identificados, na medida em que sem protocolos, os atendimentos não são orientados por regras institucionais que devem ser aplicadas por todos os profissionais, de acordo com as situações que se apresentem. Como resultado o diagnóstico, os atendimentos e encaminhamentos podem ocorrer de acordo com a personalidade profissional dos operadores da justiça ou dos membros de suas equipes, fazendo com que o acesso das mulheres aos seus direitos esteja vinculado por maior ou menor sensibilidade e conhecimento sobre a gravidade do problema da violência baseada em gênero (PASINATO; SANTOS, 2008).

Na seção seguinte a confirmação das dificuldades geradas pela falta de treinamento específico demonstradas nas áreas mais emocionais que nas técnicas.

\section{Dificuldades enfrentadas ao atender situações de violência}

Com relação as dificuldades encontradas 3 disseram não ter encontrado dificuldade e 12 disseram que sim, encontraram dificuldades que foram classificadas entre emocionais e técnicas.

Entre as dificuldades emocionais destacam-se:

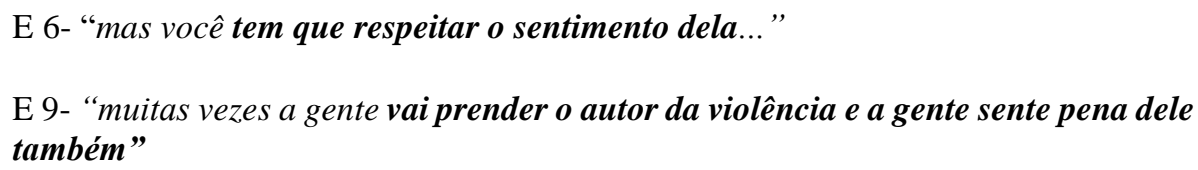

E 12- "ajudar, olha só é o desespero, ela não queria nada de papel, de procedimento burocrático, ela queria uma ajuda...... que não tinha, aí a gente se sente o que? Impotente. Nesse sentido, por que a gente conversa, dá o conselho ali, mas não somos assistente social, psicólogo pra ir até a residência dela, não temos essa autorização pra poder saber o que tá acontecendo, o que levou ele a isso!

Dentre as dificuldades classificadas como técnicas: 
E 1- “...agilidade, aqui é pra fazer rápido pra atender todos, porque nós todos aqui é não deixar nenhum atendimento sem fazer, nenhum”.

E 5- "eu acho que a maior dificuldade é em ter uma vítima que às vezes, no caso, ela não quer que tome nenhuma providencia policial e eu não ter para onde direcionala, "não se a senhora for a senhora vai ter um acompanhamento”, Não, hoje infelizmente o suporte que eu posso oferecer aqui é na parte criminal ...".

Destacada as formas de atuação da equipe recorrendo à procedimentos mais técnicos, distantes dos envolvimentos emocionais, como uma estratégia para lidar com as dificuldades em atender vítimas de violência.

Daqueles 3 que não identificaram dificuldades, destacam-se:

E 10- "Não tenho, quando o agressor chega a gente age. Não são criminosos, as vezes nem colocamos algemas, conduz ele ..."

E 14- “eu acho que não teve muitas dificuldades não, eu acho que não, só mesmo a gente encaminha pra delegacia ... quando elas vêm saber do processo a gente atende muito rápido.... acho que não tem muitas dificuldades não."

Para Rifiotis (2015, 2004), acerca dos limites da atuação, é preciso ter em conta que na grande maioria dos casos, a Delegacia da Mulher é procurada após uma série de agressões, que geralmente há reincidência, que parece não ter fim. $\mathrm{O}$ trabalho muitas vezes considerado morto, perdido (grifo nosso), que incomoda as agentes policiais e gera impotência diante dos casos de violência conjugal. Esse fenômeno começa e se desenvolve de modo invisível para as mulheres, e mesmo quando atinge uma dimensão policial, ainda assim não está completamente a seu alcance

A vítima pode retirar a queixa, nos casos previstos pela lei, e transformar todo um trabalho de investigação, tomada de depoimentos, em trabalho não utilizado Essa frustração é marcante para a caracterização da auto-avaliação das delegadas, e mostra a diferença entre a auto-identidade da instituição (polícia judiciária) e a identidade atribuída pela usuária do serviço (RIFIOTIS 2004). Muitos policiais das delegacias sentem seus trabalhos incapazes de conter a violência que se repete num ciclo sem fim (RIFIOTIS, 2015).

Outro aspecto marcante nos atendimentos das delegacias da mulher, segundo Rifiotis $(2015,2004)$ é a utilização do poder da polícia, no mecanismo da intimação para colocar ordem nas relações de poder no espaço doméstico. Acontece da seguinte maneira após denunciar uma agressão, a reclamante pede que a delegada chame o seu marido para conversar, para que ela lhe dê um conselho, um susto, assim a atividade policial é solicitada para demanda privada, pois os procedimentos das delegacias são os de fazer BO, investigar, etc. 
Assim, considerando a falta de treinamento, busca por apoios subjetivos pessoais ou técnicos, uma nova confirmação dos recursos que os entrevistados lançam mão para fazer atendimentos, segue na próxima seção.

\section{Recursos utilizados nos atendimentos}

Após a leitura das respostas, as mesmas foram classificadas entre recursos pessoais, 11 entrevistados e recursos técnicos, 4 entrevistados. Destacam-se nas respostas quanto aos recursos pessoais:

E 2- "que recursos? Não, os recursos mesmo foi habilidade né, com a percepção da dificuldade..."

E 8- "é só a ponderação, o bom senso, eu peço, "olha ta faltando com respeito", claro eu faço interferência de uma forma amistosa né, mas se insistir muito nessa deselegância o desrespeito aí eu falo com autoridade."

E 12- "eu faço terapia, me ajuda muito em relação a casos..."

Nas respostas de recursos mais técnicos destacam-se

E 3- "mas assim eu sou muito prático no trabalho, eu não adentrava muito, já passava pra equipe né, até porque essa parte que a vítima chegava precisando de um apoio que fosse de ser ouvida, receber uma orientação..."

E 4- "eu tento ouvir a vítima e incentivar falar "não, você pode mudar a situação, estuda, procura crescer, se você não pode sair agora pode sair lá na frente quando estiver trabalhando"

E 9 - “...eu já tenho isso meio que já treinado na mente... equilibrio...”

A importância dos mecanismos judiciários nos conflitos intrafamiliares e aponta para uma leitura menos criminalizada, mas que tais conflitos são a problemática. Ao longo de sua pesquisa percebeu-se a "judicialização" é apresentada como conjunto de práticas e valores, norteadores nas instituições como a Delegacia da Mulher, e que consiste fundamentalmente em interpretar a "violência conjugal" a partir de um ponto de uma leitura criminalizante e estigmatizada expressa na polaridade "vítima-agressor". (COMMAILLE, 1997). Rifiotis (2015), afirma que do ponto de vista policial, haveria uma utilização da delegacia por parte da mulher reclamante, que procurava utilizar-se da autoridade policial para obrigar o seu agressor a admitir o erro e a intermediar a pacificação da relação entre eles. A intimação era sinônimo de intimidação e a delegada neste contexto atuava em posição de árbitra, cujos procedimentos demonstravam uma leitura pessoal e circunstancial dos atos e dos sujeitos envolvidos (RIFIOTIS, 2015). 
A interpretação que busca o crime representa obstáculos para a compreensão e intervenção dos conflitos interpessoais, ela é teoricamente questionável, já que não corresponde às expectativas das pessoas atendidas nas delegacias da mulher.

\section{Sentimentos diante de situações de violência doméstica contra a mulher, por parceiro íntimo.}

De acordo com as respostas em sua grande maioria, 13 dos entrevistados, se sentem mobilizados emocionalmente de alguma forma, contra 2 que se sentem neutros. Seguem-se alguns exemplos:

E 9- "este é mais sofrido .... porque aqui envolve sofrimento principalmente de criança"

E 12- "mas eu tiro algo da minha vida pessoal também, principiante em relação a filhos, em relação a como se fiz, a mulher, porque antigamente quando...antes da lei Maria da Penha fazia reconciliações..."

E 15- "não me sinto bem né com certeza, porque uma mulher está sendo ofendida é a mesma coisa que... uma mulher tá sendo agredida a gente tá sendo agredida também né, então não se sente bem porque... solidariedade com certeza, na sociedade a mulher é o sexo frágil né, que eles falam mas..."

Ilustrando os que se sentem neutros:

E 1- "sabe que eu não tomo isso pra mim não..."

E 10- "Agimos com o agressor dependendo de como ele se comporta. Toda ação leva uma reação."

Muitos desses sentimentos relatados acompanham a questão anterior, quando na impossibilidade de lançar mão de recursos técnicos, os atendentes acabam mobilizados emocionalmente. $\mathrm{O}$ desafio é se sentirem capacitados para desempenhar os papéis que lhes são atribuídos pela vítima, não apenas no que diz acerca dos procedimentos técnicos da Lei.

Riffiotis $(2015,2004)$, ao observar recepções de delegacias e acompanhar a conversa com a delegada e psicóloga, verificou que as vítimas não desejavam que se fizesse o Boletim de Ocorrência, mas sim, desejavam uma intervenção nos conflitos conjugais. Esta necessidade da reclamante pode tornar o espaço jurídico, o da busca de acolhimento e compreensão até mediação de seus conflitos. A seção seguinte verifica os sentimentos dos entrevistados.

\section{Importância da educação em estudos feministas, história das mulheres ou estudos de gênero}

Os entrevistados compreendem que a educação em estudos feministas, pode trazer conhecimento a mulher sobre si mesma perfazendo 13 entrevistados. Já 3 não souberam dizer e acreditam que não trazem contribuições para a mulher deixar de sofrer violência.

Assim se expressam os que consideram importante: 
E 4- "eu acho sim que a mulher que tem conhecimento desses movimentos, que isso é bom pra mulher, é melhor pra ela se defender”.

E 6- "eu acho que qualquer conhecimento que envolva a auto estima é valido, né,e muito valido, porque primeiro ela vai reconhecer o que é seu valor, e nessa identificação de si mesmo ela vai respeitar o outro e ai é uma via de mão dupla...

E 15- "com certeza, a mulher tem que saber onde ela está inserida na sociedade né, o lugar dela né, que não é de violência né , que a mulher ela pode sim se empoderar né, pode ter todo o empoderamento né, pra poder seguir sua vida, que ela pode também viver sozinha, ela não tem que viver por detrás de um homem, que ela tem o seu espaço sim na sociedade, que ela tem como sobreviver por conta própria e não sempre ter o homem, como que se diz..."

Exemplificando o motivo de não considerar que tais conhecimentos possam evitar a violência:

E 8- "mas eu não vejo isso como um fator importante não, com todo respeito, porque qual o nosso público aqui hoje? Nosso público aqui hoje posso afirmar que de cada 10 casos que chegam pra nós aqui, menos de 1 eu posso dizer que sejam pessoas que são bem esclarecidas com relação aos seus direitos e deveres, a maioria não tem esse esclarecimento, então se você for buscar pra ela a questão do gênero, a questão do empoderamento da mulher, isso é uma discussão que passa muito além da sua capacidade, do seu interesse, eu vejo dessa forma".

A resposta que afirma não saber traz o seguinte pensamento:

E 7-"olha você sabe que eu nem sei te responder isso, eu acho que a educação ajudaria, vamos pensar, porque quando a cabeça abre, se talvez você saia daquele ambiente e olhe de fora assim, você vê que aquilo está errado né, injetar essa coisa na cabeça da mulher, essa coisa feminista, talvez não seria bom não porque talvez tornasse ela assim, ela achasse que pode responder aquilo a altura e talvez gerasse uma agressão maior, sabe..."

Alguns autores concordam que a maior educação feminina foi associada a maior possibilidade de violência doméstica, possivelmente pelo fato de mulheres instruídas desafiarem mais a autoridade masculina como foi comprovado na pesquisa de Cwikel, LevWiesel e Al-Krenawi (2003).

No final dos anos 80 no Brasil, ocorreu uma mudança teórica significativa nos estudos feministas ${ }^{1}$. Influenciada pelos debates norte-americanos e franceses sobre a construção social do sexo e do gênero, as feministas no Brasil começam a substituir o predicativo mulher pelo gênero. Há um consenso de que a categoria gênero abre espaço para um novo molde no estudo das questões relativas às mulheres. Enquanto o modelo patriarcal implica papéis sociais rígidos,

\footnotetext{
${ }^{1}$ Ver Paoli, Maria Célia. "As Ciências Sociais, os Movimentos Sociais e a Questão de Gênero". Novos Estudos CEBRAP, n. 31, outubro de 1991, p. 107-120; Costa, Albertina de Oliveira e Bruschini, Cristina (org.). Uma Questão de Gênero. São Paulo, Rosa dos Tempos/Fundação Carlos Chagas, 1992; Heilborn, Maria Luiza e Sorj, Bila. "Estudos de Gênero no Brasil". In: Miceli, Sérgio (org.). O Que Ler na Ciência Social Brasileira (19701995).São Paulo, Editora Sumaré/ANPOCS; Brasília, DF, CAPES, 1999, p. 183-222.
}

Barbarói, Santa Cruz do Sul, n.54, p.<171-194>,jul./dez. 2019 
enraizados culturalmente pelas diferenças biológicas entre homens e mulheres, a nova perspectiva de gênero enfatiza a diferença entre o social e o biológico.

Nota-se que a mudança na percepção da mulher, enquanto gênero, a inclui em um cenário novo e com possibilidades de novos questionamentos.

Todo um movimento internacional e de reconhecimento das desigualdades entre homens e mulheres através dos direitos humanos viabilizou os movimentos feministas, exigir no plano nacional, a implementação de inúmeros avanços. O Estado foi cobrado na responsabilidade por abusos perpetrados, tanto na esfera pública quanto na esfera privada. No Brasil, o movimento feminista teve papel importante na visibilidade do assunto, organizando seminários, debates e encontros preparatórios, e ainda, na pressão para o posicionamento do governo brasileiro nesses encontros internacionais (DE SOUZA, 2012)

Para De Souza (2012), as feministas suas lutas permitiram atingir uma rede muito mais ampla, com destaque à violência contra as mulheres e aos direitos reprodutivos. Nessa época, no processo de abertura de canais de participação social e política, iniciou se um diálogo com o Estado marcado pela criação em 1982, do Conselho Estadual da Condição Feminina, em São Paulo.

Em 1985, surgiu a primeira Delegacia Especializada da Mulher. A partir das décadas de 70 e 80, os movimentos trouxeram à tona a questão da violência contra a mulher acessível à mídia, principalmente com a repercussão da morte de Ângela Diniz.

Diante da força dos movimentos feministas e de mulheres e inúmeros documentos internacionais de proteção aos direitos das mulheres, a violência doméstica e familiar ganhou visibilidade social ao agregar números cada vez mais alarmantes. A violência conjugal é uma realidade cruel e os movimentos feministas lutaram pelo reconhecimento dos direitos das mulheres, conseguindo dar visibilidade ao fenômeno da violência (DE SOUZA, 2012).

É inegável que a conscientização de mulheres e dos movimentos formados por elas, trouxeram uma visibilidade da violência de gênero, isto é, aquela que é cometida contra a mulher. Apesar de não ser acessível a muitas mulheres violentadas é inegável também que as conquistas realizadas pelos movimentos feministas tornam um acercamento da igualdade de gênero mais próximo até para aquela mulher que não tem acesso a esses estudos ou conhecimentos. 


\section{Educação machista dos homens é responsável por se tornarem agressores.}

Os entrevistados se dividiram entre concordarem, 7 do total e 5 se dividem entre a educação machista e outros elementos que consideram constituir um agressor. Apenas 2 acreditam que não seja essa educação machista a responsável.

Para poder compreender os que concordam, destacam-se:

E 3- "pode sim, acredito que sim. É... o homem tá perdendo o seu papel sabe, eu acredito que o machismo e também a educação que ele vem de que o homem é quem manda, o homem é quem decide, isso ele não perdeu né..."

E 8- "com certeza, com certeza, "porque eu sou o dono, eu sou o macho, porque eu ponho os alimentos dentro da casa, eu que mantenho a casa, então eu dito as regras","

E 9- "com certeza, e é igual eu te falo as vezes ele não acha que é criminoso, ele não acha que está cometendo crime, ele acha que tá dentro do direito bater na mulher, porque faz parte da relação e porque ele é o homem da casa".

Destacam-se as falas dos que dividem a educação machista com outros elementos:

E 2- "eu acredito que posso ter alguma influência né, mas cada ser vai absorver de uma forma né, a gente não pode medir o machismo em todos os homens porque cada um vai absorver de uma forma,.... então há a diferença do machismo que ele tem”; "ah eu sou o homem eu sou o maioral" e com isso eu fazer o que quero com a mulher, e tem o outro que "eu sou realmente o homem, o másculo, o provedor da casa, o que seja, digamos o centro da casa”, mas que na verdade ele tenha como centro da casa a mulher, os filhos, então é bem diferente....

E 13- "não, eu não digo que seja só a cultura porque a gente sabe que tem vários homens que vivem nessa mesma cultura, nessa mesma sociedade e não são agressores. Eu acho que existe assim, um histórico familiar, transgeracional, no qual as vivências que ele teve, ele enquanto individuo, dentro daquela família que ele cresceu, o levou a se tornar essa pessoa agressiva, ou as vezes o pai era um alcoólatra que batia na mulher e tal, e ai ele começou a beber muito jovem com 12/13 anos e hoje aos 24/25, é um dependente químico, é um usuário de droga e ele teve como exemplo a violência, então na cabeça dele ele tem que tratara a mulher daquele jeito, então eu não acho que seja só a questão cultural, é uma questão também individual né.".

Michael Kaufman (1999), desenvolveu um esquema chamado de "Sete 'P' da violência dos homens", que tem por objetivo tentar compreender a complexa natureza da violência entre a população masculina contra outros homens ou contra as mulheres.

Poder patriarcal: sociedades dominadas por homens são estruturadas na hierarquia e violência de homens sobre mulheres e também sobre outros homens e na 'autoviolência', constituindo um ambiente que tem como principal função a manutenção do poder da população masculina;

Privilégios: as violências cometidas pelos homens não acontecem apenas devido às desigualdades de poder, mas também, a uma crença de merecimento de privilégios que devem ser concedidos pelas mulheres; 
Permissão: para Kaufman, a violência contra a mulher é abertamente permitida e até estimulada pelos costumes sociais, códigos penais e por algumas religiões. Do mesmo modo, a violência de homens contra outros homens é não apenas permitida, como também celebrada e banalizada em filmes, esportes e na literatura;

Paradoxo do poder masculino: para desenvolver seus poderes individuais e sociais, os homens constroem armaduras que os isolam do contato afetivo com o próximo $e$ da arena do cuidado, seja esse cuidado para outros ou para ele mesmo;

Armadura psicológica da masculinidade: constituída a partir da negação e rejeição de qualquer aspecto que possa parecer feminino;

Pressão psíquica: os homens são educados desde a infância para não experienciar ou expressar emoções e sentimentos como medo, dor e carinho. A raiva, por outro lado, é uma das poucas emoções permitidas e, assim, outras emoções são canalizadas por esse canal;

Experiências passadas: o fato de muitos homens crescerem observando atos de violência realizados por outros homens - muitas vezes seus pais - pode caracterizar tais situações como a norma a ser seguida.

Dessa forma, fica evidente que os homens estão presentes no contexto da violência, em diferentes lugares, sendo produto e alvo dos padrões de subjetividade orientados pelos modelos de gênero e pelas relações desiguais de poder em nossa sociedade.

Apesar da visível emancipação feminina não se pode negar as discrepâncias entre homens e mulheres ainda prevalentes. Entre estas se destacam a diferença salarial, mesmo quando exercem as mesmas funções, a legitimação social em torno à supremacia masculina, que, por vezes, os induz a ter que provar sua heterossexualidade e seu lugar de poder (TONELI, 2010), muitas vezes por meio a violência, entre outras discrepâncias. Os discursos dos(as) funcionários(as) corroboram com o exposto. De acordo com as observações na delegacia, há uma proliferação do sistema patriarcal aonde os homens consideram se superiores às mulheres, mantendo uma relação de poder para com a sua esposa ou companheira.

Ademais, verificou-se nos relatos dos(as) funcionários(as) participantes a transgeracionalidade da violência. Estudos apontados por Wendt dos Santos e Ojeda Ocampo Moré (2011), são análogos à constatação anterior. Segundo os autores, crianças e adolescentes que vivenciam situações de violência tendem a reproduzi-las, pois consideram este padrão de estrutura familiar correto/normal. É possível, de acordo com os autores, que a perpetuação deste ciclo seja decorrente dos valores sociais calcados em um sistema patriarcal.

Nas palavras de Saffioti, "o patriarcado não se resume a um sistema de dominação, modelado pela ideologia machista. Mais do que isto, ele é também um sistema de exploração. Enquanto a dominação pode, para efeitos de análise, ser situada essencialmente nos campos 
político e ideológico, a exploração diz respeito diretamente ao terreno econômico" (SAFFIOTI, 2004, p. 50).

Diante da apresentação dos resultados verificam-se aproximações e distanciamentos de estudos pesquisados. Existe uma percepção dos envolvidos no processo de acolhimento e encaminhamento da mulher que passa por direções da Lei, mas também são formadas pelas posturas e abordagens à partir da prática e vivências com este público específico.

Os atendimentos são feitos na maior agilidade possível e tanto na Delegacia, porta de entrada, quanto na Vara, a parte processual acontece na máxima brevidade. As equipes estão engajadas em realizar seu trabalho de acordo com a LMP e ficam atentas na identificação e informação às reclamantes.

Ficou evidente na percepção de todos os entrevistados que há déficit quanto a efetividade da proteção, mas no que se refere à realização do trabalho, este é feito a contento.

A efetividade deve ser auxiliada pelos gestores, já que há demanda de investimentos financeiros para a contratação de mais pessoas, incluindo a equipe psicossocial presente diariamente na Delegacia e na Vara. Com base nos resultados da pesquisa e dos achados desta realidade local as considerações finais apresentam um compilado da pesquisa.

\section{Considerações Finais}

Os entrevistados concordam que existe a necessidade de treinamento específico para exercer atividade dentro desses espaços, destinados às mulheres, o que não aconteceu até então, com a maioria. Suas condutas são pautadas na LMP e desenvolvidas, no dia a dia, por meio de suas experiências. Foi unânime a afirmação de que ambos os locais necessitam de uma equipe multidisciplinar permanente, isto é, na Delegacia Especializada a presença de um Psicólogo e Assistente Social é fundamental para o correto acolhimento à vítima, como também no auxílio aos integrantes da equipe. Na Vara não é diferente, já que também são realizadas audiências e a participação da equipe multidisciplinar apoiaria o juiz em suas tentativas de conciliação, como na identificação, no caso de coação da vítima.

Outra unanimidade das respostas dos entrevistados vem da questão da prevenção. Eles acreditam que a presença da equipe multidisciplinar e um programa permanente de prevenção, informando, tanto homens como mulheres acerca da violência, como ela se configura nas atitudes, como são punidos os agressores e quais consequências, gerariam efeitos positivos nas famílias e nos relacionamentos, além de permitir o acompanhamento e a possibilidade de tratar os "agressores". 
A efetivação da LMP, na prática, também foi apontada já que se trata de uma lei completa, prevendo uma rede de atendimento, monitoramento, acompanhamento, prevenção, atendimentos dos envolvidos, o que não acontece, ainda, na cidade.

A necessidade de uma casa de acolhimento, no município, é urgente já que muitas mulheres não têm para onde ir e estão ameaçadas de morte. Somente a medida protetiva se apresenta como insuficiente em muitos casos, principalmente quando a vítima não tem para onde ir, ou precisa acionar a Polícia Militar.

A segurança pública, por meio do policiamento, conta ainda com poucas viaturas o que pode atrasar um chamado de urgência.

Outro fator importante, citado na pesquisa, é a necessidade de acompanhamento dos agressores, considerando que muitos deles são homens que não tem consciência de que as suas atitudes são enquadradas em um crime. $\mathrm{O}$ acompanhamento poderia evitar, em muitos casos, a reincidência, pois existem homens que são trabalhadores, chefes de família, mas falta-lhes instrução ou orientação. O próprio juiz da Vara afirmou que acompanhar agressores poderia ser a medida mais eficiente, já que a maioria dos casos não resulta na prisão do agressor.

Por fim, a percepção dos entrevistados, que é pessoal, colhida de forma individualizada, não deixou de retratar um extrato coletivo, pois, neste espaço de violência, todos sentem de alguma forma a violência e a aproximação das questões íntimas abertamente declaradas. Sofrem as mulheres, sofrem os filhos, sofrem os que fazem parte do acolhimento.

A violência contra a mulher não é apenas contra aquela mulher, que foi até uma das instituições pesquisadas, é da esposa, da mãe e da avó, pode estar em todas as famílias. Estes espaços destinados as elas, muitas vezes busca o "crime", pela natureza do serviço que devem ser prestados e pelas funções atribuídas. Se percebe ainda que neste mesmo local, a vítima busca acolhimento, por isso deve ser um espaço de pesquisa e ações do Estado para a melhoria de condições de trabalho das equipes e o efetivo acolhimento e encaminhamento dessas mulheres.

É notória a necessidade de treinamento das equipes como a permanência exclusiva de uma equipe multidisciplinar na Delegacia, primeiro contato da vítima, como na Vara, acompanhando os desdobramentos dos casos, apoiando, treinando, esclarecendo os membros das equipes, como também participando efetivamente de ações de prevenção. A violência contra a mulher ainda está longe de ser combatida, mas ações como as previstas na LMP, podem ser implementadas para se conseguir avançar no combate a este mal que fragiliza, adoece e morta suas vítimas. 


\title{
THE DIFFICULTIES OF SERVICE TEAMS ABOUT VIOLENCE AGAINST WOMEN IN GURUPI-TO
}

\begin{abstract}
This work interviewed the Stick and Delegacy teams specialized in the care of women victims of violence in Gurupi, in order to seek their perceptions about the difficulties encountered. This is a qualitative research, carried out with 15 operators from the two institutions, who responded to an interview with a semi-structured script, being analyzed through the floating reading of the content analysis of Bardin. Their findings agree with other studies in the same perspective, demonstrating that the perceived difficulties are more related to the care and reception of the victim than in the accomplishment of the legal procedures, necessary and foreseen by the LMP. In this way, the data corroborate the request of the implementation of the service network for women that is still underdeveloped in this locality.
\end{abstract}

Key words: violence against women; attendance; teams.

\section{DIFICULTADES EN LA ATENCIÓN ACERCA DE LA VIOLENCIA CONTRA LA MUJER, EN GURUPI-TO}

\section{Resumen}

Este trabajo presenta los resultados de las entrevistas semiestructuradas a los equipos de la Vara y la Comisaría Especializadas en la atención a la mujer víctima de violencia en Gurupi, con el objetivo de buscar sus percepciones acerca de las dificultades encontradas. Se trata de una investigación cualitativa, realizada con 15 operadores de las dos instituciones. Las respuestas fueron analizadas a partir de la lectura flotante y del análisis de contenido, de Bardin. Sus hallazgos concuerdan con otras investigaciones en la misma perspectiva, demostrando que las dificultades percibidas están más relacionadas a la atención y acogida a la víctima que en la realización de los procedimientos legales, necesarios y previstos por la LMP. De esta forma los resultados corroboran para la solicitud de la implementación de la red de atención a la mujer, en el municipio, que aún se presenta poco desarrollada en esta localidad.

Palabras clave: violencia contra la mujer; servicio; equipos.

\section{REFERÊNCIAS}

ALLEN, M.; DEVITT, C. Intimate partner violence and belief systems in Liberia. Journal of Interpersonal Violence, v. 27, n. 17, p. 3514-3531, 2012.

ALVES, M. C. L.; DUMARESQ, M. L.; SILVA, R. V. As lacunas no enfrentamento à violência contra a mulher: análise dos bancos de dados existentes acerca da violência doméstica e familiar. 2016.

ALVES, M. J. V. et al. Evolution and analysis of cultural and cognitive factors related with domestic violence against women. Journal of interpersonal violence, n.0886260516645570, 2016.

BARDIN, L. Análise de conteúdo (Edição revista e actualizada). Lisboa: Edições 70, 2011.

BARSTED, L. L. Lei Maria da Penha: uma experiência bem-sucedida de advocacy feminista. Lei Maria da Penha: comentada em uma perspectiva jurídico-feminista. Rio de Janeiro: Lumen Juris, p. 13-38, 2011. 
BARSTED, L. L.; PITANGUY, J. O progresso das Mulheres no Brasil 2003-2010. Rio de Janeiro: CEPIA/Brasília: ONU Mulheres, 2011.

BECHO, J. et al. Serendipitous intervention: Qualitative findings from the study of dynamic patterns of husband-to-wife abuse. Journal of family violence, v. 28, n. 3, p. 243-251, 2013. BLAY, E. A. Violência contra a mulher e políticas públicas. Estudos avançados, v. 17, n. 49, p. 87-98, 2003.

BOONZAIER, F.; DE LA REY, C. Woman abuse: The construction of gender in women and men's narratives of violence. South African Journal of Psychology, v. 34, n. 3, p. 443-463, 2004.

BOSCH-FIOL, E.; FERRER-PÉREZ, V. A. New map of the myths about gender violence in XXI century. Psicothema, v. 24, n. 4, p. 548-554, 2012.

BONOMI, A. E. et al. Health care utilization and costs associated with physical and nonphysical-only intimate partner violence. Health services research, v. 44, n. 3, p. 10521067, 2009.

BRASIL, MINISTÉRIO DA SAUDE. SECRETARIA DE POLÍTICAS DE SAÚDE. Violência intrafamiliar: orientações para a prática em serviço.Violência intrafamiliar orientações para a prática em serviço. Cadernos de Atenção Básica, n. 8, (Série A - Normas e Manuais Técnicos, n. 131). Brasília, DF, 2002.

BRASIL. PRESIDÊNCIA DA REPÚBLICA. Lei 11.340/2006 de 07 de agosto de 2006. O Código Penal e a Lei de Execução. Brasília, 2006. Disponível em:

<http://www.planalto.gov.br/ccivil_03/_Ato2004-2006/2006/Lei/L11340.htm>. Acesso em: 25 Jan. 2018.

BRASIL. SECRETARIA DE POLÍTICAS PARA AS MULHERES (SPM). Lei No11.489, de 2007. Brasília, 2007.

BRASIL, MINISTÉRIO DA JUSTIÇA. SECRETARIA DE POLÍTICAS PARA AS MULHERES. Norma técnica de padronização das delegacias especializadas de atendimento às mulheres — 25 anos de conquistas — Deams. Brasília: Ministério da Justiça, 2010.

BRASIL, SENADO FEDERAL. OBSERVATÓRIO DA MULHER CONTRA A VIOLEENCIA. Panorama da violência contra as mulheres no Brasil: indicadores nacionais e estaduais, 2016.

COMMAILLE, J. Violences intra-familiales: l'exigence d'une politique publique. Cahiers de la Sécurité Intérieur, n. 28, 1997.

CWIKEL, J.; LEV-WIESEL, R.; AL-KRENAWI, A. The physical and psychosocial health of Bedouin Arab women of the Negev area of Israel: the impact of high fertility and pervasive domestic violence. Violence Against Women, v. 9, n. 2, p. 240-257, 2003.

DE SOUZA, L. T. Demanda Penal e Violência Doméstica e Familiar Cometida contra a Mulher no Brasil. Revista Artemis, v. 13, n. 1, 2012. 
EFE, Ş. Y. Domestic violence against women and women's opinions related to domestic violence. 2010.

ESQUEDA, C. W.; HARRISON, L. A. The influence of gender role stereotypes, the woman's race, and level of provocation and resistance on domestic violence culpability attributions. Sex Roles, v. 53, n. 11-12, p. 821-834, 2005.

FERNÁNDEZ, M. Cultural beliefs and domestic violence. Annals of the New York Academy of Sciences, v. 1087, n. 1, p. 250-260, 2006.

GRANJA, E.; MEDRADO, B. Homens, violência de gênero e atenção integral em saúde. Psicologia: Sociedade, v. 21, n. 1, 2009.

GROSSI, M. P. Violência, gênero e sofrimento. In: Educação e direitos humanos: discurso críticos e temas contemporâneos, p. 121-134, 2008.

HEISE, L. L. Violence against women: an integrated, ecological framework. Violence against women, v. 4, n. 3, p. 262-290, 1998.

JANKOWSKI, P. J. et al. Religiosity, intolerant attitudes, and domestic violence myth acceptance. International Journal for the Psychology of Religion, v. 21, n. 3, p. 163-182, 2011.

KAUFMAN, M. The Seven'P's of Men's Violence. Men's Development Network Limited, 2013.

KNICKMEYER, N.; LEVITT, H.; HORNE, S. G. Putting on Sunday best: The silencing of battered women within Christian faith communities. Feminism; Psychology, v. 20, n. 1, p. 94-113, 2010.

KORPI, W.; FERRARINI, T.; ENGLUND, S. Women's opportunities under different family policy constellations: Gender, class, and inequality tradeoffs in western countries reexamined. Social Politics: International Studies in Gender. State; Society, v. 20, n. 1, p. 1-40, 2013.

KRUG, E. G. World report on violence and health. Genebra: World Health Organization, 2002.

MACHADO, L. Z. Atender vítimas, criminalizar violência: dilemas das delegacias da mulher. Departamento de Antropologia, Universidade de Brasília, 2002.

MASSUNO, E. Delegacia de Defesa da Mulher: uma resposta à violência de gênero. São Paulo, Humanitas, 2002.

MEGÍAS, J. L.; MONTAÑÉS, P. Perception of battered women on power asymmetry in their couples and its relation to violence: a preliminary study. Anales de Psicología/Annals of Psychology, v. 28, n. 2, p. 405-416, 2012. 
MODI, M. N.; PALMER, S.; ARMSTRONG, A. The role of Violence Against Women Act in addressing intimate partner violence: a public health issue. Journal of Women's Health, v. 23, n. 3, p. 253-259, 2014.

ORGANIZAÇÃO DAS NAÇÕES UNIDAS. Declaração das Nações Unidas de 1993 sobre a Eliminação da Violência contra a Mulher. ONU, 1993.

ORGANIZAÇÃO DAS NAÇÕES UNIDAS. Escritório das Nações Unidas contra Drogas e Crime, ONU, 2014.ORGANIZAÇÃO MUNDIAL DA SAÚDE- OMS- Relatório Mundial de saúde. 2005.

PASINATO, W. "Rede de serviços para enfrentamento da violência contra as mulheres em Belo Horizonte: um estudo de caso”. In: LEOCÁDIO, E.;LIBARDONI, M. (Org). O desafio de construir redes de atenção às mulheres em situação de violência. Brasília: Agende, 2006. p. 131-167.

PASINATO, W. Oito anos de Lei Maria da Penha. Entre avanços, obstáculos e desafios. Estudos Feministas, v. 23, n. 2, p. 533-545, 2015.PASINAT0, W. Violência Contra a Mulher e Acesso à Justiça. Estudo comparativo sobre a aplicação da Lei Maria da Penha em cinco capitais. In Coordenação Geral CEPIA- Cidadania, Estudos, Pesquisa, Informação e Ação. Fundação Ford Apoio, 2013.

PASINATO, W.; SANTOS, C. M. Mapeamento das delegacias da mulher no Brasil. Núcleo de Estudos de Gênero Pagu, Universidade Estadual de Campinas PAGU/UNICAMP, 2008.

PETER, S.; DROBNIČ, S. Women and their memberships: Gender gap in relational dimension of social inequality. Research in Social Stratification and Mobility, v. 31, p. 3248, 2013.

PIMENTEL, S. Convenção sobre a Eliminação de Todas as Formas de Discriminação Contra a Mulher. São Paulo: CEDAW, 1979.

PIOVESAN, Flávia. Direitos humanos: desafios da ordem internacional contemporânea. Direitos humanos, v. 1, p. 15-37, 2006.

PITANGUY, J.; HERINGER, R. Diálogo regional da América Latina e Caribe sobre direitos reprodutivos e violência contra a mulher: papéis e responsabilidade de homens jovens e adultos. Rio de Janeiro: Cidadania, Estudo, Pesquisa, Informação e Ação, 2002.

RIFIOTIS, Theophilos. Violência, Justiça e Direitos Humanos: reflexões sobre a judicialização das relações sociais no campo da "violência de gênero". cadernos pagu, n. 45, p. 261-295, 2015.

RIFIOTIS, T. As delegacias especiais de proteção à mulher no Brasil e a «judiciarização» dos conflitos conjugais. Sociedade e Estado, v. 19, n. 1, p. 85-119, 2004.

T1 NOTÍCIAS. Palmas lidera entre as capitais brasileiras no ranking de violência contra a mulher. Palmas. 2018. 
TOCANTINS. TRIBUNAL DE JUSTIÇA -TO. TJ-TO aprova criação de vara. 2009.

Disponível em : <http://pm.to.gov.br/noticia/2009/4/3/tj-to-aprova-criacao-de-vara/>.Acesso em: 16 Jan. 2018.

TOCANTINS. POLÍCIA CIVIL DO TOCANTINS. Gestor de Procedimentos de Polícia

Judiciária. 2017. Disponível em <http://gerpol.ssp.to.gov.br/pj-net-to/> Acesso ao PJ@ Net.

TONELI, M.J.F. et al (Ed). Atendimento a homens autores de violência contra mulheres: experiências latino americanas. UFSC/CFH/NUPPE, Campus Universitário Trindade, 2010.

VALOR-SEGURA, I.; EXPÓSITO, F.; MOYA, M. Victim blaming and exoneration of the perpetrator in domestic violence: The role of beliefs in a just world and ambivalent sexism. The Spanish journal of psychology, v. 14, n. 1, p. 195-206, 2011.

VENTURI, G. et al (Org). Pesquisas de opinião: a mulher brasileira nos espaços público e privado. São Paulo: Fundação Perseu Abramo, 2004. Disponível em:

<http://library.fes.de/pdf-files/bueros/brasilien/05629-introd.pdf>. Acesso em: 16 Jan. 2018.

WOMEN, U. N. Progress of the world's women: In pursuit of justice. 2011.

WENDT DOS SANTOS, A. C.; OJEDA OCAMPO MORÉ, C. L. Repercussão da violência na mulher e suas formas de enfrentamento. Paideia, v. 21, n. 49, 2011.

WORDEN, A. P.; CARLSON, B.E. Attitudes and beliefs about domestic violence: Results of a public opinion survey: II. Beliefs about causes. Journal of interpersonal violence, v. 20, n. 10, p. 1219-1243, 2005.

YAMAWAKI, N. et al. Perceptions of domestic violence: The effects of domestic violence myths, victim's relationship with her abuser, and the decision to return to her abuser. Journal of Interpersonal Violence, v. 27, n. 16, p. 3195-3212, 2012.

Data de recebimento: $11 / 12 / 2018$

Data de aceite: $13 / 11 / 2019$

\section{Sobre as autoras:}

Laslei Aparecida Teles Petrilli é professora adjunto I da Universidade Unirg no curso de Graduação em Psicologia. Endereço Eletrônico: lasleitp@gmail.com

Helga Midori Iwamoto é graduada em Licenciatura Plena em Matemática pela Universidade Federal do Espírito Santo (2003), mestre em Administração pela Universidade Federal do Espírito Santo (2006), doutora em Administração de Empresas pela Universidade Presbiteriana Mackenzie (2013), pós-doutora em Desenvolvimento Regional pela Universidade Federal do Tocantins (2019). Atualmente é professora adjunta IV na Universidade Federal do Tocantins. Tem experiência na área de Feminismo, atuando principalmente nos temas: políticas públicas e terceiro setor. Endereço Eletrônico: helga@uft.edu.br 